\title{
“仁者壽”：儒家的德性健康之 醫學模式
}

曹永福

醫學模式是人們從總體上認識健康和疾病及其相互轉化的哲 學觀點, 包括健康觀、疾病觀、診斷觀、治療觀及死亡觀等。（景 匯泉、宋漢君，2013，22）人類醫學發展到今天, 主要經歷了神 靈主義醫學模式、自然哲學醫學模式、機械論醫學模式、生物醫 學模式和生物一心理－社會醫學模式等五個階段。《中外醫學哲 學》刊發了李瑞全教授的〈中國文化中的人論與醫學 : 儒家之醫 學模式〉（李瑞全，2015，49）一文, 認為中醫是 “生機整體論 的醫藥模式”, 文章指出: 中國傳統醫學的特色是 “醫乃仁術”, 儒家倫理對於作為一種文化的中國傳統醫學有著重要影響, 中國 一切傳統文化都是 “仁心所創發，醫學之道亦如是” ，在此基礎 上，提出了 “仁心通於醫學” 的中國文化中的醫藥模式，筆者認 為這種醫藥模式即李先生所指的 “儒家之醫學模式”。李先生在 文中細緻分析了 “心靈疾病” 的診斷和治療。他指出：“人類心 靈之最突出表現是對其他人和其他生命的同情共感” , 人類具有 的這種 “心靈之感通能力” , 使之具有 “內在而超越的價值” , 這體現了儒家 “人之為人” 的價值理念。這種 “心靈現象”也可 以產生 “傷害或被傷害”, 從而有所謂的“心靈疾病”，而對“心 靈疾病” 治療的出發點是使病者之心靈 “可以與醫者和他人相感

曹永福, 山東大學醫學院醫學倫理學系教授, 中國濟南, 郵編：250012。

《中外醫學哲學》XIII:2 (2015 年) : 頁 79-82。

(c) Copyright 2015 by Global Scholarly Publications. 
通, 使心靈擺脱局限和扭曲, 恢復天機活潑, 生意暢通的狀態”。 受李先生深乿醫學哲學分析的啟發，筆者嘗試提出 “德性疾病” 和 “德性健康” 之概念, 作為李先生儒家醫學模式中 “心靈疾 病” 和 “心靈健康” 的回應。因為從概念上看, 李先生所言 “心 靈” 之外延應該包含 “德性” ，“德性” 其實是其所謂的 “心 靈” 的一種。

人是否會罹患 “德性疾病” ? 什麼是 “德性疾病” ? 為什麼 會䍜患 “德性疾病” ? 如何恢復 “德性健康” ? 李先生在文中提 出：“平常的一些違背倫常或合理的規範的表現, 即是一種病態 和疾病。生命不能順適地與他人他物和世界和諧地共處並存, 此 即是疾病。”已初涉這個問題, 但仍需要做進一步的分析和探討。

世界衛生組織認為，除了軀體健康、心理健康和社會適應良 好外, 還要加上 “道德健康”。(李恩昌、李花枝, 1992，43） 其內容包括：健康者不以損害他人利益來滿足自己的需要，具有 辨別真與偽、善與惡、美與醜等是非觀念, 能按照社會行為的規 範準則來約束自己及支配自己的思想和行為。其實, “德性健康” 的理念早已載於儒家經典中, “仁者壽” 是孔子的重要命題：“知 者樂水; 仁者樂山。知者動, 仁者靜; 知者樂, 仁者壽。” (《論 語 - 雍也》) 在儒家看來, 一個人具有仁愛德性, 可以長壽, 具 有仁愛德性的人, 必然長壽, “德性健康” 有利於健康長壽。德 性存在缺陷和問題, 即罹患所謂的 “德性疾病”, 必然會影響健 康和長壽。這也被現代研究所證實：“巴西學家阿塞托·馬丁斯 曾通過 10 年的時間進行研究, 對 583 名被指控犯有各種貪污、受 賄罪的官員與同樣數目的廉潔官員進行比較, 發現前者中因生病 而死亡的佔 $60 \%$ ，而後者只佔 16\%。”（楊志達，2007，69）

德性是重要的人性。人具有 “物性”、“生物性”、“動物 性” 和“區別於動物的特性” 四級人性。（王海明，2008，528） 德性顯然屬於第四級人性。德性是一個人的道德人格, 是一個人 在長期的道德行為中表現出來的比較穩定的心理自我。這樣看 
來, “德性疾病” 並不是一個人在一時一事上存在道德問題, 一 個人如果在某一行為上存在道德缺陷, 我們尚不能説他已罹患 “德性疾病” ; 一個人罹患 “德性疾病” ，是在系列行為中存在 道德問題和缺陷, 這種問題和缺陷需要表現出一定的穩定性和傾 向性。這種 “德性疾病” 表現在, 一方面, 行為者明知自己的行 為不道德或存在道德缺陷而仍然時常為之, 另一方面, 行為者每 當做了不道德的事或存在道德缺陷的行為而一直不覺, 或認為並 非不道德或存在道德缺陷。前者屬 “明知故犯”, 道德惡意大, 後者屬 “不覺異化”, 病情更重。“德性疾病”之所以稱之為“疾 病”, 是因為, 一方面這些不道德和存在道德缺陷的行為對他人、 對社會有害, 另一方面, 更值得注意的是, 這些行為會導致行為 者精神緊張、恐懼、焦慮、內疚等不良心態, 從而影響其本人的 健康。現代醫學已經證實：“這種精神狀態極易引起神經中樞、 內分泌系統功能的失調, 削弱其免疫系統的防病能力, 最終在惡 劣心境的重壓和各種身心疾病的折磨下, 或早衰, 或失去健康, 甚至喪生。”（楊志達，2007，69）

人們之所以罹患 “德性疾病”, 究其原因至少有社會道德和 制度環境、個人道德意識和修養等諸多方面。一方面, 一個道德 惡劣、制度扭曲的 “黑暗” 社會環境, 會普遍使人行為規範缺失, 無所適從, 德性淪喪而罹患 “德性疾病”。另一方面, 個人道德 認知混亂, 道德情感淡漠, 道德修養低下, 會使之行不道德之事 而不覺, 甚至故意做不道德之事而罹患 “德性疾病”。這樣, 德 性疾病的診治和德性健康的維護, 既需要優良社會道德制度的構 建, 又需要個人加強道德修養, 豐富和提升自己的 “道德智慧”。 對此, 儒家的“仁政”倫理和“仁心”倫理可以給予有益的啟示。

\section{參考文獻}

王海明：《新倫理學》, 北京 : 商務印書館, 2008。WANG Haiming. New Ethics (Beijing: The Commercial Press, 2008). 
李恩昌、李花枝: 《世界衛生組織提出健康新概念, 道德健康是健康的 重要內容》·《中國醫學倫理學》·1992 年, 第 3 期, 頁 43 ○ LI Enchang and Li Huazhi. "The New Concept of Health Was Put forward by WHO, Moral Health is the Important Content of Health,” Chinese Medical Ethics, 3 (1992), p.43.

李瑞全：〈中國文化中的人論與醫學：儒家之醫學模式〉, 載范瑞平編, 《中外醫學哲學》, 2015 年, 第 13 卷, 第 2 期, 頁 49-66 LEE Shui Chuen. "Humanity and Medicine in Chinese Culture: A Confucian Medical Model," International Journal of Chinese \& Comparative Philosophy of Medicine, edited by FAN Ruiping, 13:2(2015), pp.49-66. 景匯泉、宋漢君: 《醫學導論》, 北京: 北京大學醫學出版社, 2013 。 JING Huiquan and SUN Hanjun. An Introduction to Medicine (Beijing: Peking University Medical Press, 2013).

楊志達：《醫學新理念：道德健康》, 《決策與資訊》, 2007 年, 第 4 期 , 頁 69 ○YANG Zhida. “Medical New Concept: Moral Health,” Decision and Information, 4(2007), p.69. 